\title{
The Digital Mapping of Ukrainian Soils on the Base of High Resolution Space Images
}

\author{
Stanislav Truskavetsky \\ National Scientific Center “Institute for Soil Science and Agrochemistry Research named after O.N. Sokolovsky”, Kharkiv 61024, \\ Ukraine
}

\begin{abstract}
The first Ukrainian using experience of multispectral space scanning for digital soil mapping is described in this paper. Methodical approaches for detailed soil observation of Ukrainian forest regions are elaborated based on modern mapping principles. For the first time in Ukraine, digital soil maps based on GIS (geographic information system) were obtained for individual farms. In GIS based on space images and digital relief models, the medium-scale and large-scale soil maps were created by geo-statistical methods. According to elaborated methods, modern digital soil mapping should provide all combined works: remote sensing and traditional soil observations. The modern digital soil mapping should be based just on quantitative principles: on remote sensing data, geomorphologic field parameters, and chemical analyses. The methodological approaches, which were used for the first time in Ukraine during digital soil mapping by remote sensing methods, are described in this paper.
\end{abstract}

Key words: Digital soil map, remote sensing, space image, GIS-technologies, digital relief model.

\section{Introduction}

Ukraine is agrarian country. There are largest European reserves of chernozems just in Ukraine. At the same time space sphere develops in Ukraine. Now Ukrainian scientists study the possibilities of space images in monitoring of agrarian resources. Scientists from National Scientific Center "Institute for Soil science and Agrochemistry Research named after O.N. Sokolovsky" (Kharkiv-city, Ukraine) already have series of developments in remote sensing of soil cover.

Generally effective nature management and its major component-agriculture are impossible without fast operating, fast restored, objective information about land condition in Ukraine. Fast accumulation obtaining of information is possible only by remote sensing methods. Ukraine has a scientific and technical potential for the development of modern land informational systems based on geographic

Corresponding author: Stanislav Truskavetsky, Ph.D., research field: remote sensing of soil cover. E-mail: space1975@mail.ru. information technologies and satellite survey data. For such systems, it is necessary to emphasize the fact that satellite data are of little value without land-based observations. Ground-based and space-based information are two basic components of land information systems, they should be developed dynamically and harmonically.

The main tendencies in remote sensing method application are the development of computer decoding and soil mapping methods. The purpose of our research is to study the possibilities of multispectral scanning for soil monitoring and soil maps improvement. Monitoring of soil surface should be based on correlation between soil optical characteristics and content of different elements, for example, in soil. We worked out an algorithm for digital soil mapping, based on geostatistical analysis of three SPOT bands (green, red and infrared).

\section{Methods}

Research was on the forest zone (Polissya) of Ukraine. The soil cover of this natural zone is very contrasting and contains podzolic acid soils. In our 
investigation we used remote sensing data from French satellite SPOT in three bands: green band (500-590 nm), red band (610-680 nm), infrared band (790-890 nm) with resolution-20 m for digital soil mapping.

The different information layers (Fig. 1) were created in GIS (geographic information system).

The additional layers are topographical maps, land-use plans, and old archive soil maps. Soil analyses were carried out: soil organic carbon content (humus), granulometric composition, total free iron content. In GIS the digital relief model was created. The relationships between soil parameters and remote sensing data were determined by means of software statistica. The final results (digital soil maps) were obtained on the basis of auto-classification geo-statistical methods in GIS.

\section{Results}

During office stage research various objects were detected. In GIS, by means of satellite images (red and infrared bands) on the basis of NDVI (normalized difference vegetation index) the fields, which did not have vegetation at the moment of scanning, were determined by Eq. (1).

$$
\mathrm{NDVI}=\left(\mathrm{V}_{3}-\mathrm{V}_{2}\right) /\left(\mathrm{V}_{3}+\mathrm{V}_{2}\right)
$$

where: $V_{3}$-the value of spectral brightness coefficient in the infrared band, $V_{2}$ - the value of spectral brightness coefficient in the red band [1-3].

If the value of index NDVI is less than 0 , then fields are to be without vegetation. We selected just such fields for our investigation. The whole map information was integrated into GIS in the form of individual layers. Beforehand on the space image the points of soil samples and soil profiles were selected. In GIS, the digital relief models of the research territory were created for further digital soil mapping.

During field research works the objectives of investigation were marked in a geographic frame of reference. We took samples of the soil surface and of

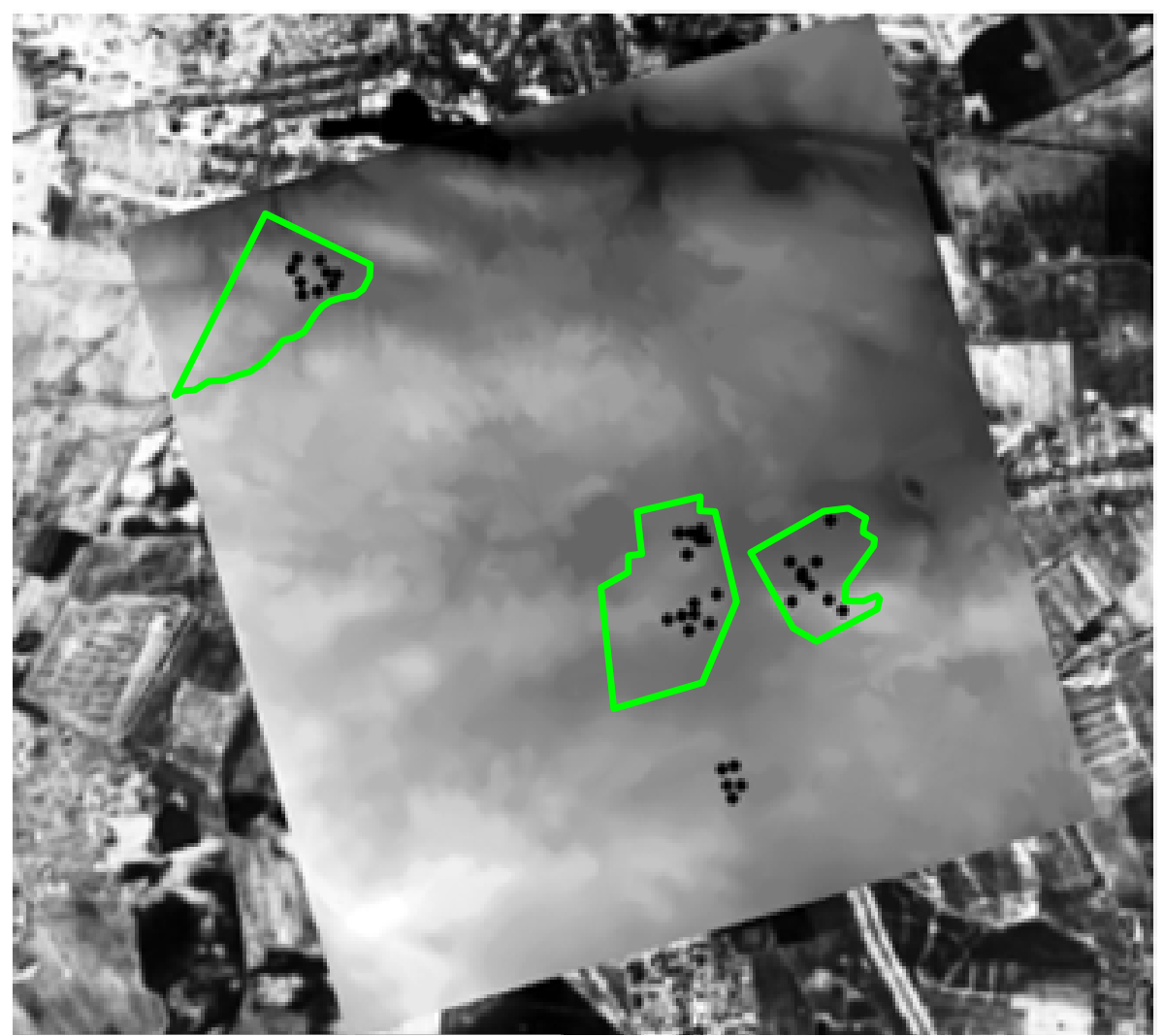

Fig. 1 The composite image in GIS (scale-1:25000): space image in red band (first layer), digital relief model (second layer) and location of soil samples with contours of fields № 1, 2, 3 (upper layer). 
the soil profile. Each spatial point of soil sampling was marked by navigation equipment (i.e., GPS). We classified soils according to the Ukrainian soil classification.

On a space raster image all spatial points (one pixel) have a spectral brightness coefficient, which was determined for every band $\left(V_{1}, V_{2}, V_{3}\right)$.

In the geo-information system TNT-lite on the basis of three bands of multispectral space scanning, the soil maps were created by geo-statistical analysis for each individual farm (Figs. 2-4).

The represented soil maps are submitted without legends in this paper because soils were called according to the Ukrainian soil classification.

Act now in Ukraine classification of soils is very different from the generally accepted international soil classification WRB (world reference base). The basis of the Ukrainian and international soil classification put different principles of diagnosis and assessment of soil. Classifications have different hierarchical levels and approaches to soil allocable to these levels. Ukrainian classification based more on the color of soil, but international soil classification based on chemical properties of the soil, so there is a substantial difference in names of soils. Ukrainian names of soils are not to be understood by scientists from Europe or the US, so not listed in this paper.

Indeed, the classification of soils, especially Ukrainian, largely based on qualitative information (subjective information), than quantitative. But we are developing new approaches not to soil classification but to soil mapping, which is based on several blocks of quantitative information: laboratory and analytical data on soil properties, quantitative geo-morphological values from digital relief models, the brightness values of space images and mathematical models.

We used the digital relief model for final results (final variant of digital soil map, precise and correct boundaries between different soils). In practice we established additional soil profiles for verification of

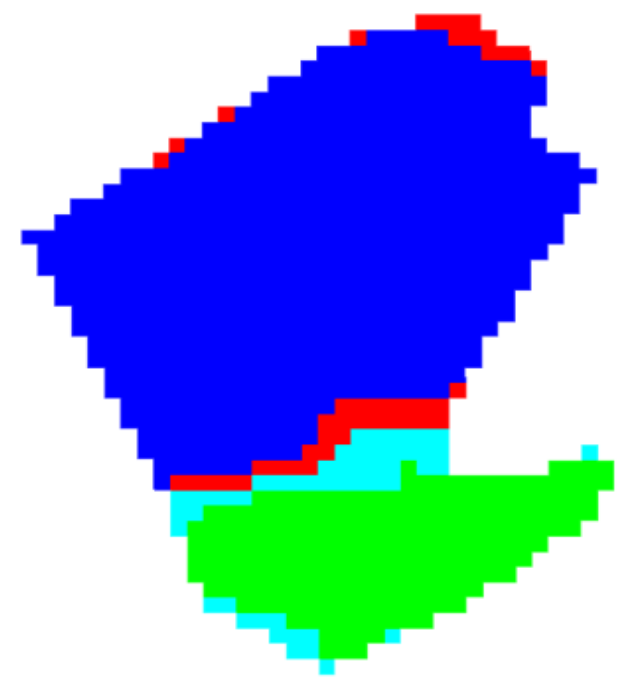

Fig. 2 The digital soil map for field № 1.

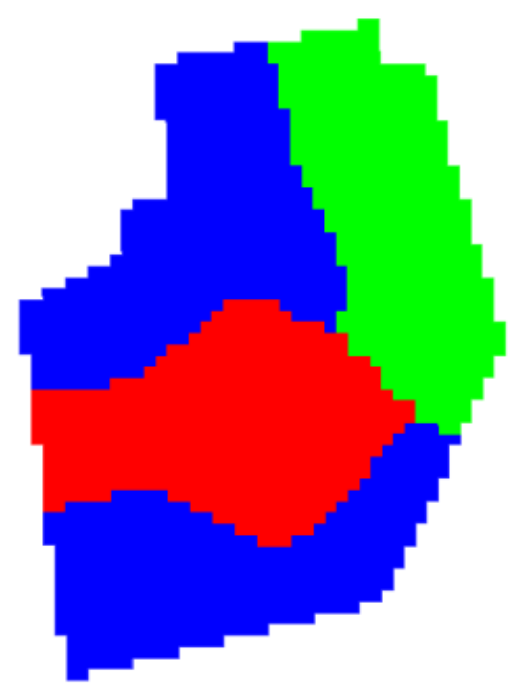

Fig. 3 The digital soil map for field № 2.

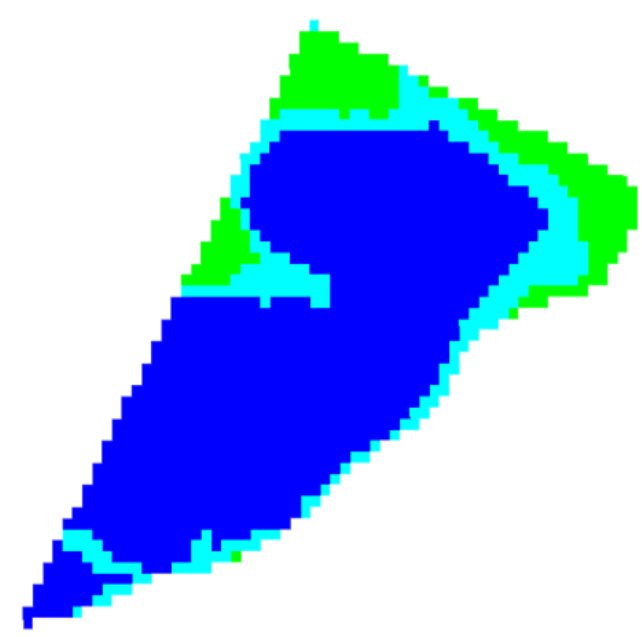

Fig. 4 The digital soil map for field № 3. 
obtained results. The accuracy of the soil maps, first of all, depends on the resolution of the satellite image. The resolution of SPOT satellite images is $20 \mathrm{~m}$. The accuracy of the location is 5-7 $\mathrm{m}$ according to the GPS device. Based on the fact that the accuracy of the traditional (outdated approach) soil mapping at a scale of 1: 25, 000 is $75 \mathrm{~m}$ (Ukranian reference data), the new digital soil maps derived from satellite images, we are quite satisfied.

\section{Conclusion}

Thanks to remote sensing we have the possibility of operative creation of precision digital soil map. The digital maps of some soil elements supply the base soil map with additional information. New approaches to digital soil mapping based on the use of just quantitative data in GIS. We elaborated different digital soil maps for other climatic zones of Ukraine.

For the first time in Ukraine digital soil maps on the base of GIS were obtained for individual farms. Digital soil maps of individual fields should be used in the system of precision farming. Monitoring of soil surface should be based on correlation between soil optical characteristics and different soil parameters. Ukraine is characterized by a variety of climatic conditions. In our state it is possible to allocate, as a minimum four main soil-climatic zones. Therefore available land of the state exhibits a very wide spectrum of soils, and also natural and agricultural vegetation. The condition of natural resources requires the constant monitoring for the prevention of natural disasters, introduction and realization of nature protection measures. Modern remote sensing data of high quality and resolution and spatial soil information may be used on the basis of geo-information systems.

Contribution by foreign specialists in the remote sensing and soil mapping sphere would be rather useful for Ukrainian experts in agrarian sphere.

\section{References}

[1] Murphy, R. J., and Wadge, G. 1994. “The Effects of Vegetation on the Ability to Map Soils Using Imaging Spectrometer Data.” Int. J. Remote Sens. 15 (1): 63-86.

[2] Shanahan, J. F., Schepers, J. S., Francis, D. D., Varvel, G. E., Wilhelm, W. W., Tringe, J. M., Schlemmer, M. R., and Major, D. J. 2001. "Use of Remote-Sensing Imagery to Estimate Corn Grain Yield.” Agronomy Journal 93: 583-9.

[3] Sripada, R. P., Heiniger, R. W., White, J. G., and Weisz, R. 2005. "Aerial Color Infrared Photography for Determining Late-Season Nitrogen Requirements in Corn.” Agronomy Journal 97: 1443-51.

[4] Truskavetsky, S. R. 2003. "To the Problem of the Large-Scale Mapping of Polissya Soils Based on the Modern Technology.” News of Agrarian Science 8: 74-6.

[5] Truskavetsky, S. R., Gichka, M. M., and Byndych, T. Y. 2005. "Lines of Improvement of Remote Sensing for Soil Mapping and Monitoring.” News of National Agrarian University 81: 176-80.

[6] Truskavetsky, S. R., Gichka, M. M., and Byndych, T. Y. 2006. "The Modern Opinion at the Informational Supplying of Soil Monitoring.” News of Agrarian Science 4: 87-9.

[7] Truskavetsky, S. R., Byndych, T. Y., Gichka, M. M., and Kalyuga, S. V. 2008. “The Methodic of Large-Scale Soil Mapping of Ukraine on the Base of Remote Sensing Data." News of Kharkiv National Agrarian University 1: 123-9.

[8] Shatokhin, A. V., and Lyndin, M. A. 2001. "Conjugate Study of Chernozems of Donbass by Ground and Remote Sensing Methods.” Soil Science 9: 1037-44. 